\section{Attenuation of Peripheral Venous Cannulation Pain: A Review of Various Strategies in Practice}

\section{Nadeem Zaidi*}

Royal Bournemouth and Christchurch Hospital, Bournemouth, England

\begin{abstract}
Securing venous access is one of the basic and core skills for the anaesthetist. As anaesthetists we should understand the importance of pain control during peripheral venous cannulation and try our level best to ensure that patients are comfortable during this intervention. Moreover anaesthetists are more comfortable and familiar regarding use of local anaesthetics and other techniques to control peripheral venous cannulation pain. They can well understand the importance of anaesthetising a calm patient compared with an anxious surgical patient whose level of anxiety are further increased by insertion of a peripheral venous cannula.

Keywords: Pain; Peripheral venous cannulation
\end{abstract}

\section{Introduction}

In modern medicine more and more emphasis has been laid on safe delivery of quality clinical services. Quality in anaesthetic practice is difficult to define. Conventionally or traditionally it is being monitored by analysis of anaesthesia related morbidity \& mortality and any adverse incident happened in the perioperative period. Anaesthetist regard quality in their work as alleviation of patient's anxiety and stress preoperatively, keeping them comfortable and haemodynamically stable during surgery, creation of favourable working conditions for surgery, pain free recovery period and early resumption of normal physiology.

Patient centered anaesthesia outcome measures are more important to judge the quality in anaesthetic services. According to one study which measured the quality in anaesthetic services through a patient derived questionnaire, patient perception of quality in anaesthesia is related to communication with anaesthetist (attention, confidence, information, addressing of patient's concerns), management of postoperative nausea vomiting and pain [1]. In

*Corresponding author: Nadeem Zaidi, Royal Bournemouth and Christchurch Hospital, Bournemouth, England, Tel: +44 1202303626; E-mail: drnadeemzaidi@hotmail.com

Citation: Zaidi N (2015) Attenuation of Peripheral Venous Cannulation Pain: A Review of Various Strategies in Practice. J Anesth Clin Care 2: 010.

Received: March 14, 2015; Accepted: July 30, 2015; Published: August 13, 2015 another study patients regarded post-operative nausea vomiting and pain as the most undesirable aspects of anaesthesia [2]. After an uneventful recovery from surgery majority of the patients do not recall any perioperative event but all they remember is their first intervention in theatre which is the pain related to peripheral venous cannulation.

This mandatory but trivial intervention assumes more importance in needle phobic patients having a high anticipatory fear of the procedure. Poor management of pain and anxiety related to venepuncture can produce extreme physiological responses [3] and chronic neuropathic pain [4]. The memory of a traumatic venepuncture may lead to the development of a needle phobic personality which may affect their future engagement with hospital services.

This review is focused on the importance of pain alleviation related to peripheral venous cannulation in adult patients. Various methods and strategies in practice in this regard are also discussed (Table 1).

\begin{tabular}{|c|c|}
\hline \multicolumn{2}{|c|}{ Peripheral Venous Cannula Pain Alleviation } \\
\hline Methods & Available Strategies \\
\hline a) Non pharmacological methods & $\begin{array}{c}\text { Nonspecific/general distraction } \\
\text { Specific distraction } \\
\text { Valsalva manoeuvre, cough trick, audio visual } \\
\text { distraction }\end{array}$ \\
\hline b) Physical methods & $\begin{array}{l}\text { Cold/ice application } \\
\text { Vapocoolant sprays }\end{array}$ \\
\hline c) Pharmacological methods & $\begin{array}{c}\text { Intradermal/subcutaneous injection } \\
\text { Local anaesthetic agents, bacteriostatic saline } \\
\text { Transdermal/topical medications } \\
\text { EMLA, amethocaine, rapydan patch } \\
\text { NSAIDS (diclofenac, ibuprofen, piroxicam) } \\
\text { Capsaicin } \\
\text { Combinations of medicines } \\
\text { EMLA \& capsaicin } \\
\text { Entonox }\end{array}$ \\
\hline d) Others & Smaller v bigger cannula \\
\hline
\end{tabular}

Table 1: Peripheral venous cannula pain alleviation various methods and strategies.

\section{Strategies in Practice}

Peripheral venous cannulation is a commonly performed invasive procedure in hospitalised patients. It facilitates the administration of fluid and medicine. The procedure is associated with pain and discomfort which is normally self-limiting and settles down quickly.

Over the years many strategies have been developed to reduce the pain of peripheral venous cannulation involving both pharmacological agents and non-pharmacological techniques with variable results. Sometimes combinations of techniques are practised to produce the desired result.

Distraction of patient is an old and time tested manoeuvre and worked well in most of the patients. It can be a nonspecific distraction e.g., general discussion with patient during venous cannulation. Cough trick is a very handy and easily performed distraction technique. Patient's cooperation, understanding and timing of venous cannulation with the cough reflex are important for its success. It is equally effective in adults and older children [5]. 
Audio visual distraction techniques are also effective to relieve pain and anxiety during venous cannulation [6].

Valsalva manoeuvre is performed by attempting to exhale against a closed airway. This can be done by keeping the mouth close and pinching the nose while trying to breathe out. Performing valsalva manoeuvre prior to peripheral venous cannulation reduces the pain of venous cannulation. Pain reduction with valsalva can be explained with neuroanatomical, pharmacological and electro physiological factors involving cardiopulmonary or sinoaortic baroreceptors. They are activated with increase in intra thoracic pressure during valsalva manoeuvre. Experimental work have suggested that a close coupling exists between the system controlling cardiovascular functions and those modulating perception of pain as activation of either cardiopulmonary baroreceptor or sinoatrial baroreceptors reflex arc induces antinociception [7].

A no studies $[8,9]$ have shown the success of valsalva manoeuvre in reducing the venepuncture pain and recommended the use of this easy intervention before venous cannulation. Patient's understanding and successful performance of the procedure holds the key for an optimum result. Compared with topical Eutectic Mixture of Local Anaesthetics (EMLA) use, valsalva manoeuvre produced similar results regarding pain reduction of peripheral venous cannulation [10].

Vapocoolant sprays are topical anaesthetic agents. Rapid evaporation of these volatile liquids from the skin surface produces a localised drop in temperature. This produces a temporary interruption of pain sensation, possibly through desensitisation of pain receptors or activation of ion channels involved in pain transmission [11]. The most commonly used vapocoolants are ethyl chloride, fluorohydrocarbon, and alkane mixtures (use in acute sports injuries). They produce immediate skin anaesthesia thus facilitating peripheral venous cannulation. They are readily available and handy to use but their flammability, vasoconstrictive properties and inconsistent results are the main limiting factors regarding their wide spread use $[11,12]$.

Intradermal/subcutaneous administration of local anaesthetic works well in a selected group of cooperative patients who can withstand the pain or discomfort of local anaesthetics with a hypodermic needle $(25-30 \mathrm{G})$. It subsequently facilitates the placement of a larger bore ( 16 or $14 \mathrm{G}$ ) cannula. The procedure works well in experienced hands as it can produce a local haematoma and distort the anatomy thus making the procedure more difficult. Use of local anaesthetics may be associated with allergic reaction and systemic toxicity.

Different local anaesthetics (lidocaine, chloroprocaine, bupivacaine) have been used to facilitate peripheral venous cannulation [13]. Lidocaine $(0.5-2 \%)$ is the most commonly used local anaesthetic. Sodium bicarbonate $\left(\mathrm{NaHCO}_{3}\right)$ is sometimes added to buffer acidic lidocaine thus reducing the discomfort associated with its use. Bacteriostatic $0.9 \%$ normal saline is a suitable alternative agent in this regard. It has benzyl alcohol as a preservative agent which have additional local anaesthetic property $[14,15]$.

Topical application of EMLA (Eutectic Mixture of Local Anaesthetics) is a widely practised method to reduce the pain associated with peripheral venous cannulation. Eutectic mixture has a melting point lower than that of any of its components. EMLA is a combination of lidocaine $2.5 \%$ and prilocaine $2.5 \%$. In combination its melting point is below room temperature and therefore both local anesthetics exist as liquid form rather than as crystals. Upon topical application penetration and subsequent systemic absorption of both prilocaine and lidocaine are enhanced over that which would be seen if each component in crystalline form was applied separately as a $2.5 \%$ topical cream [16].

Topical application of EMLA (Eutectic Mixture of Local Anaesthetics) cream was found to be effective in relieving pain associated with punch biopsies, split thickness skin grafting, laser hair removal, sharp wound debridement, leg ulcers, decubitus ulcers, post-op wounds, diabetic ulcers and burns [17]. It has also shown its beneficial results in reduction of pain associated with peripheral venous cannulation both in adults and paediatric population $[18,19]$. It is applied at the desired site with an occlusive dressing, 45-60 minutes before cannulation. Its use is limited by its vasoconstrictive properties. It also carries a rare risk of methemoglobinemia [18]. It is more effective when compared with topical piroxicam gel but showed equipotent results when compared with topical capsaicin in the management of venepuncture pain [20,21].

EMLA cream is also used in combination with other topical analgesic agents and non-pharmacological techniques to achieve a synergistic effect. One study demonstrated that combine use of EMLA and topical capsaicin ointment significantly reduces the pain of peripheral venous cannulation when compared with their individual effects. Capsaicin produces sensitization of sodium channels towards the effects of local anaesthetics. When it is used in combination with topical anaesthetic preparations a prolonged and predominant sensory block is produced [22].

Topical preparations of nonsteroidal anti-inflammatory agents (diclofenac, ibuprofen, piroxicam) and topical capsaicin have also been used with variable results regarding pain alleviation of peripheral venous cannulation $[20,23]$.

Amethocaine (tetracaine) is an ester local anaesthetic which is more lipophilic than either lidocaine or prilocaine. Its $4 \%$ preparation (ametop) is available for topical application. Ametop has a rapid onset of action (30-45 $\mathrm{min}$ ) after topical application with an occlusive dressing) and longer duration of action (4-6 h). It causes localised erythema, itching and oedema due to its vasodilatory action. Systemic adverse effects are rarely seen after topical application due to slow absorption and tissue hydrolysis of amethocaine [16].

It has been successfully used as a topical analgesic agent for various dermatological procedures. It has also shown promising results regarding alleviation of peripheral venous \& radial artery cannulation pain and discomfort.

Compared with EMLA, topical application of $4 \%$ amethocaine has shown either equal or better results in reducing the pain during venous cannulation, especially in children $[17,24]$.

Rapydan is a eutectic mixture of $7 \%$ lidocaine and $7 \%$ tetracaine. The medicated patch of rapydan is activated upon exposure to air. This thermogenic reaction produces a localised warming effect thus promoting the absorption of local anaesthetic through the skin. Compares with other topical local anaesthetic preparations this heat assisted drug delivery system is likely to provide a rapid onset of action [25]. Improved pharmacokinetic profile of rapydan in terms of its rapid onset of action (20-30 minutes) made it a suitable alternative to both EMLA and Ametop regarding provision of dermal anaesthesia for venous cannulation $[25,26]$. Its use is associated with localised 
erythema which is related to both heat and histamine release. Whether this cutaneous vasodilation facilitates the venous cannulation needs further work up and research.

Entonox is an established short term analgesic agent. It is effective on a selected group of patients to minimize the pain and discomfort of peripheral venous cannulation. Other handy but less practised technique is use of ice pack at the site of venous cannulation.

\section{Conclusion}

As anaesthetist we should appreciate the importance of pain alleviation during peripheral venous cannulation. We should be familiar with various techniques and methods available in this regard. Choice of appropriate strategy for the patient depends upon his level of understanding, cooperation, anxiety, apprehension level and surgical requirements. These fine changes in anaesthetic practice will have a positive impact regarding improving the quality of our clinical work.

\section{References}

1. Hocking G, Weightman WM, Smith C, Gibbs NM, Sherrard K (2013) Measuring the quality of anaesthesia from a patient's perspective: development, validation, and implementation of a short questionnaire. $\mathrm{Br} \mathrm{J}$ Anaesth 111: 979-989.

2. Macario A, Weinger M, Carney S, Kim A (1999) Which clinical anesthesia outcomes are important to avoid? The perspective of patients. Anesth Analg 89: 652-658.

3. Hart PS, Yanny W (1998) Needle phobia and malignant vasovagal syndrome. Anaesthesia 53: 1002-1004.

4. Gohil S, Balasubramanian S (2012) Case report and literature review of chronic neuropathic pain associated with peripheral venous cannulation. Anaesthesia 67: 1395-1397.

5. Usichenko TI, Pavlovic D, Foellner S, Wendt M (2004) Reducing venipuncture pain by a cough trick: a randomized crossover volunteer study. Anesth Analg 98: 343-345.

6. Agarwal A, Yadav G, Gupta D, Tandon M, Singh PK, et al. (2008) The role of a flash of light for attenuation of venous cannulation pain: a prospective, randomized, placebo-controlled study. Anesth Analg 106: 814-816.

7. Basaranoglu G, Basaranoglu M, Erden V, Delatioglu H, Pekel AF, et al. (2006) The effects of Valsalva manoeuvres on venepuncture pain. Eur J Anaesthesiol 23: 591-593.

8. Vijay VR, Agnihotri M, Kaur S, Bhalia A (2013) Effect of Valsalva maneuvre prior to peripheral intra venous cannulation on intensity of pain. Nursing and Midwifery Research Journal 9: 143-151.

9. Agarwal A, Sinha PK, Tandon M, Dhiraaj S, Singh U (2005) Evaluating the efficacy of the valsalva maneuver on venous cannulation pain: a prospective, randomized study. Anesth Analg 101: 1230-1232.

10. Suren M, Kaya Z, Ozkan F, Erkorkmaz U, Arıcı S, et al. (2013) Comparison of the use of the Valsalva maneuver and the Eutectic Mixture of Local Anesthetics $\left(E M L A^{\circledR}\right)$ to relieve venipuncture pain: a randomized controlled trial. J Anesth 27: 407-411.
11. Hijazi R, Taylor D, Richardson J (2009) Effect of topical alkane vapocoolant spray on pain with intravenous cannulation in patients in emergency departments: randomised double blind placebo controlled trial. BMJ 338: 215.

12. Selby IR, Bowles BJ (1995) Analgesia for venous cannulation: a comparison of EMLA (5 minutes application), lignocaine, ethyl chloride, and nothing. J R Soc Med 88: 264-267.

13. Brown D (2004) Local anesthesia for vein cannulation: a comparison of two solutions. J Infus Nurs 27: 85-88.

14. Halm MA (2008) Effects of local anesthetics on pain with intravenous catheter insertion. Am J Crit Care 17: 265-268.

15. Burke SD, Vercler SJ, Bye RO, Desmond PC, Rees YW (2011) Local anesthesia before IV catheterization. Am J Nurs 111: 40-45.

16. Tadicherla S, Berman B (2006) Percutaneous dermal drug delivery for local pain control. Ther Clin Risk Manag 2: 99-113.

17. Yeoh CN, Lee CY (2012) Pain during venous cannulation: Double-blind, randomized clinical trial of analgesic effect between topical amethocaine and eutectic mixture of local anesthetic. J Anaesthesiol Clin Pharmacol 28: 205-209.

18. Schreiber S, Ronfani L, Chiaffoni GP, Matarazzo L, Minute M, et al. (2013) Does EMLA cream application interfere with the success of venipuncture or venous cannulation? A prospective multicentre observational study. Eur J Pediatr 172: 265-268.

19. Speirs F, Taylor KH, Joanes DN, Girdler NM (2001) A randomised, double-blind, placebo controlled, comparative study of topical skin analgesics and the anxiety and discomfort associated with venous cannulation. $\mathrm{Br}$ Dent J 190: 444-449.

20. Dutta A, Puri GD, Wig J (2003) Piroxicam gel, compared to EMLA cream is associated with less pain after venous cannulation in volunteers. Can $\mathrm{J}$ Anaesth 50: 775-778.

21. Agarwal A, Yadav G, Gupta D, Tandon M, Dhiraaj S, et al. (2007) Comparative evaluation of myolaxin and EMLA cream for attenuation of venous cannulation pain: a prospective, randomised, double blind study. Anaesth Intensive Care 35: 726-729.

22. Gupta D, Kishore K, Rastogi S, Singh PK, Agarwal A, et al. (2013) A comparative evaluation of local application of the combination of eutectic mixture of local anesthetics and capsaicin for attenuation of venipuncture pain. Anesth Analg 116: 568-571.

23. Agarwal A, Dhiraaj S, Kumar A, Singhal V, Singh U (2006) Evaluation of a diclofenac transdermal patch for the attenuation of venous cannulation pain: a prospective, randomised, double-blind, placebo-controlled study. Anaesthesia $61: 360-362$.

24. Newbury C, Herd DW (2009) Amethocaine versus EMLA for successful intravenous cannulation in a children's emergency department: a randomised controlled study. Emerg Med J 26: 487-491.

25. Ravishankar N, Elliot SC, Beardow Z, Mallick A (2012) A comparison of Rapydan ${ }^{\circledR}$ patch and Ametop ${ }^{\circledR}$ gel for venous cannulation. Anaesthesia 67: 367370.

26. Sawyer J, Febbraro S, Masud S, Ashburn MA, Campbell JC (2009) Heated lidocaine/tetracaine patch (Synera, Rapydan) compared with lidocaine/prilocaine cream (EMLA) for topical anaesthesia before vascular access. $\mathrm{Br} \mathrm{J}$ Anaesth 102: 210-215. 